\title{
Compatibility of the Citizens of Isfahan with the Implementation of Social Distance in Order to Deal with the Epidemic of Covid-19 Disease
}

\begin{abstract}
Introduction: The spread of coronavirus and its effects on social, cultural, political and economic conditions and human health have led to a comprehensive approach to eliminate and reduce the devastating consequences of it, as a central issue in the world. The aim of the present study was to investigate the compatibility of the citizens of Isfahan with the implementation of social distance in order to deal with the epidemic of Qovid-19 disease.

Methods: The present study is a quantitative approach and descriptive strategy and correlation and field tactics. A total of 300 households were selected as the sample size by stratified random sampling method and the data collection tool was a researcher-made questionnaire that after confirming the validity, its reliability was confirmed with Cronbach's alpha coefficient of 0.803 . In the method of data analysis through descriptive and inferential statistics using SPSS-26 software in the form of Chi -square, Eta and Spearman tests, the relationship between social distance and demographic variables was investigated.

Results: The findings show that $27 \%$ of the statistical sample had observed social spacing and except for the demographic variable, the marital status of the respondents, which has a very significant significant relationship with social distance, had a significant relationship between other demographic variables and social spacing. Has not.

Conclusion: Crisis management of infectious diseases, policy-making and macro-management and comprehensive management should be done and steps should be taken towards strategic foresight; Those in charge of culture, education and the media should make every effort to strengthen society's social responsibility.
\end{abstract}

Keywords:Compatibility, COVID-19 Disease, Social Distance, Pandemic ${ }^{\{1\}}$
Article Info

Authors:

Shahryari $\mathrm{N}^{1} \odot$

Azarafrooz $\mathrm{M}^{2} \odot$

Tabesh $\mathrm{S}^{3^{*}} \odot$

Vakili $\mathrm{A}^{4} \oplus$

Shamakhi $\mathrm{S}^{5} \odot$

Received:2020.4.20

Accepted:2020.5.20

E-Published:2020.6.9

\footnotetext{
Affiliations

*Assistant Professor, Department of Sport Management, Faculty of Sport Sciences, University of Mazandaran, Babolsar, Iran.

s.tabesh@umz.ac.ir
}

Citation Subjects:

$\{1\}$ Disease Outbreaks 
فصلنامه يرستار و گيزشك در رزم / بهار 99 / سال هشتم

ISSN:

مقاله يثوهشى

\section{سازگًارى شهروندان شهر اصفهان با اجراى فاصله خذارى اجتماعى در راستاى مقابله با همه كيرى بيمارى كوويد-19}

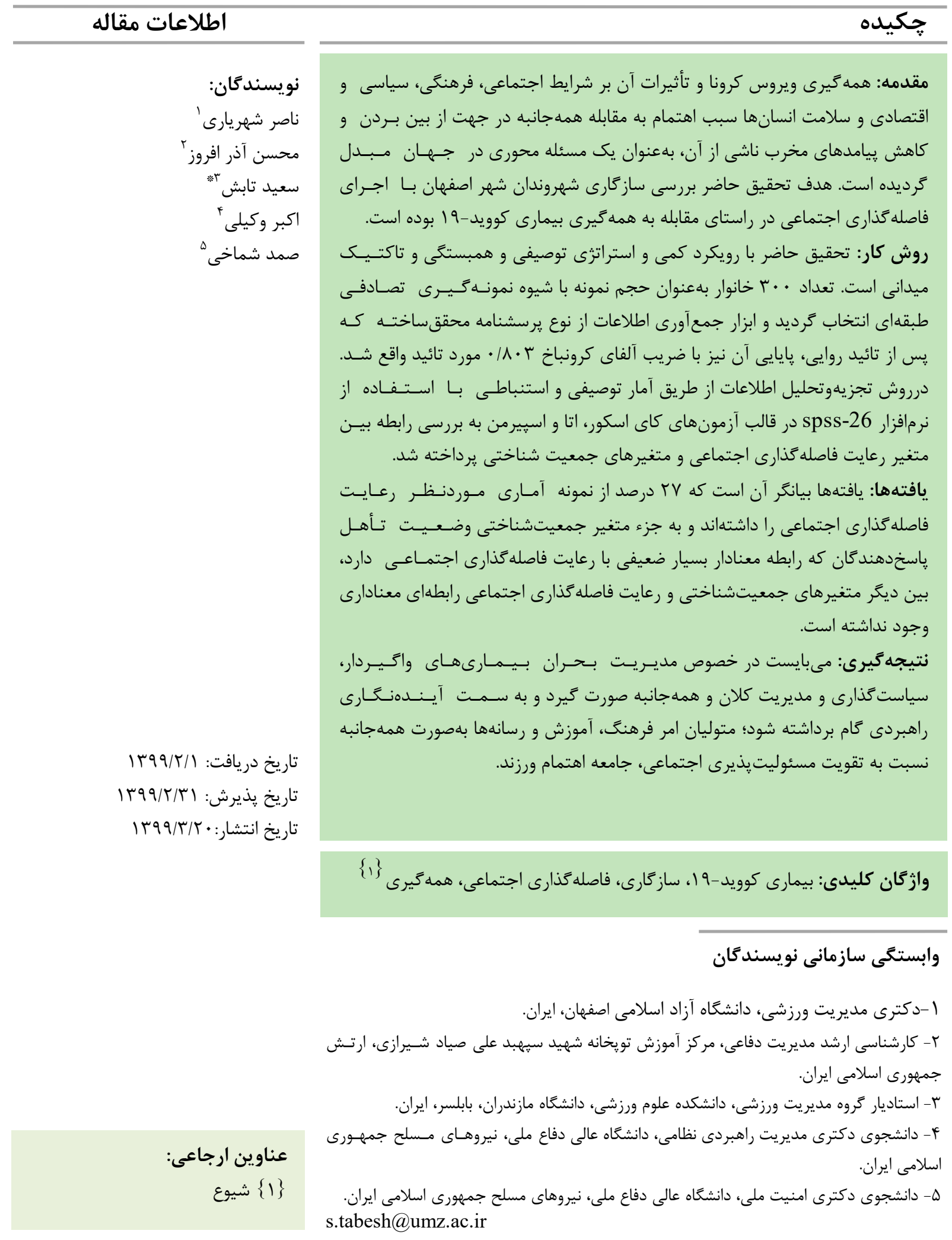




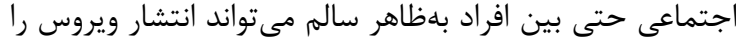

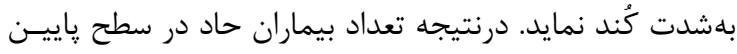

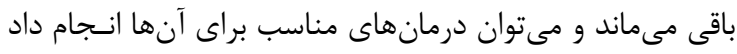

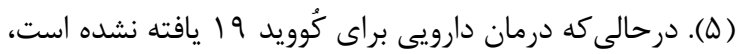

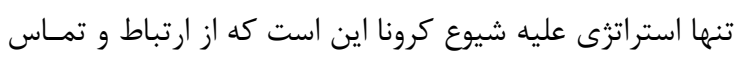

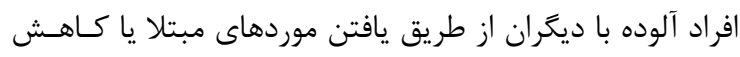

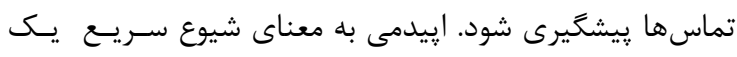

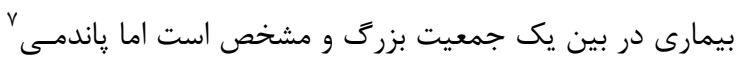

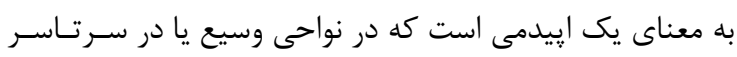

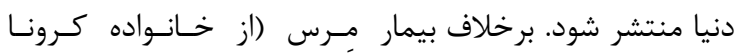

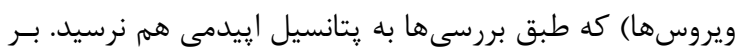

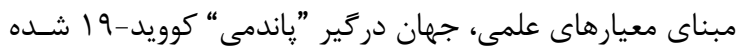

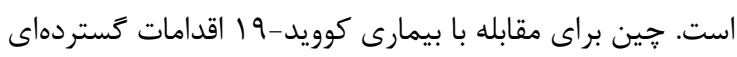

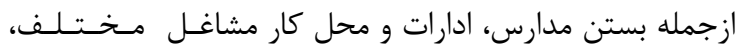

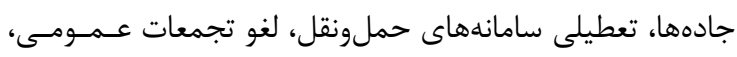

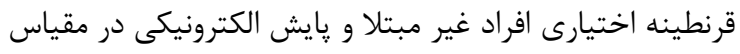

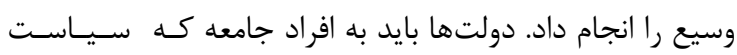

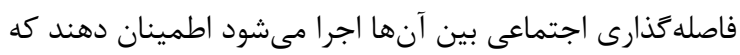

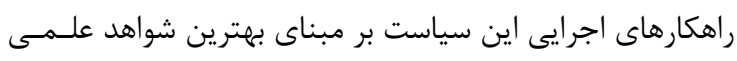

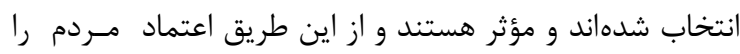

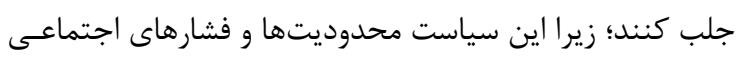

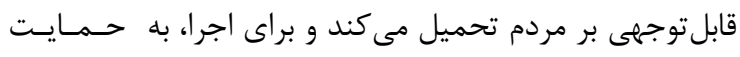

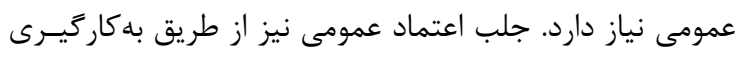

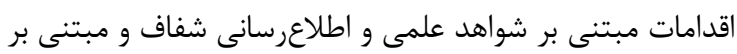

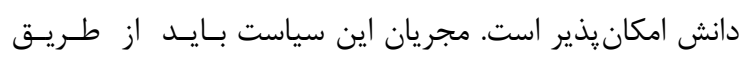

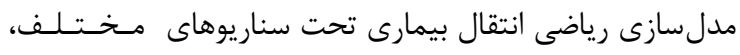

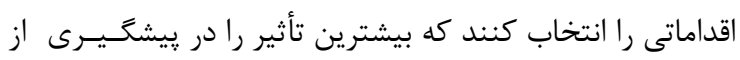

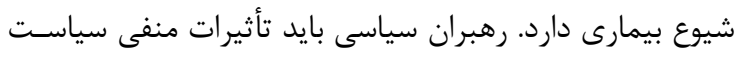

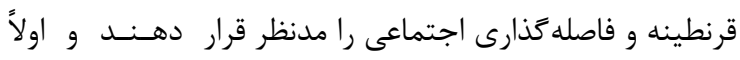

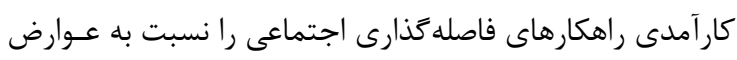

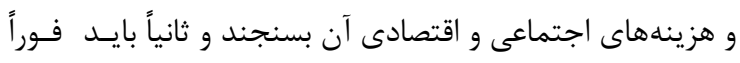

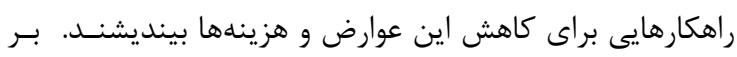

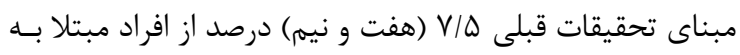

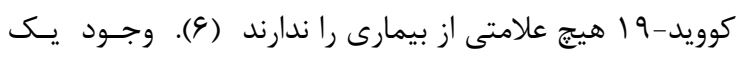

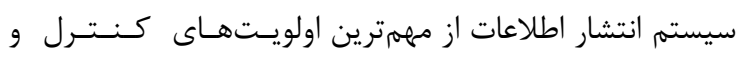

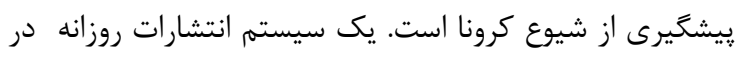

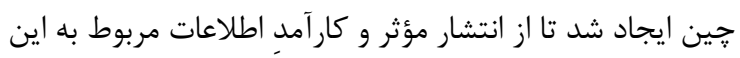

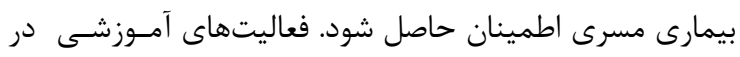

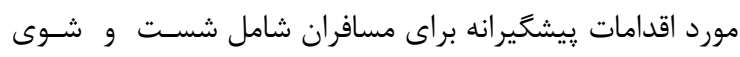

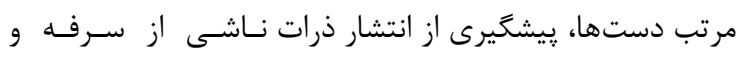

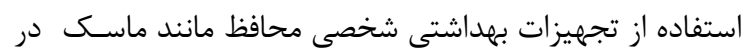

7- Pandemic
مقدمه

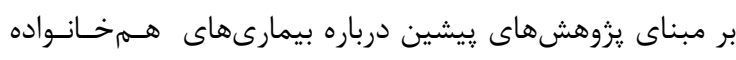

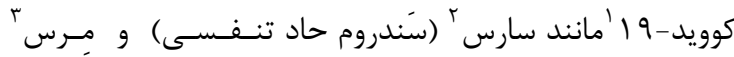

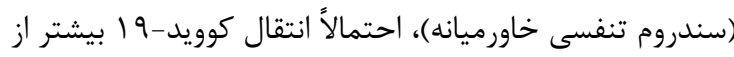

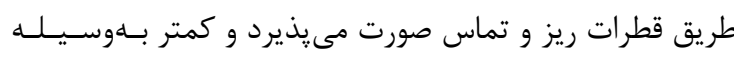

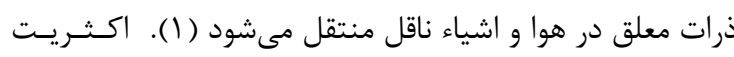

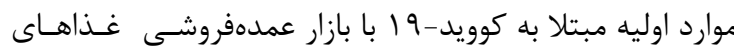

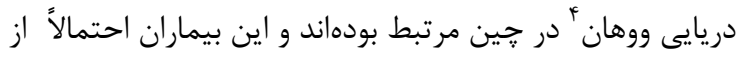

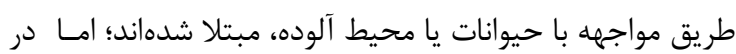
ادامه انتقال بيمارى از طريق تماس انسان با انسان اتفاق افتـاده

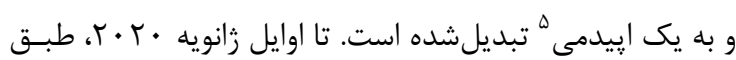

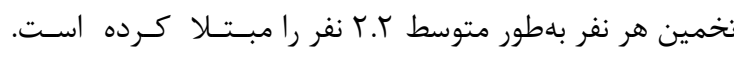

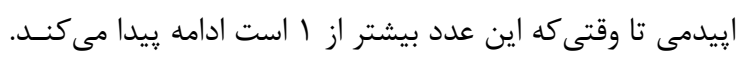

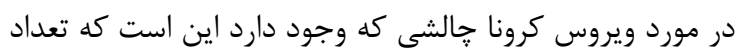

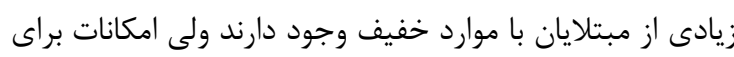

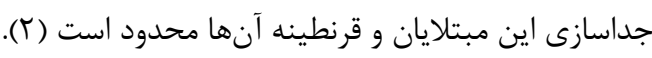

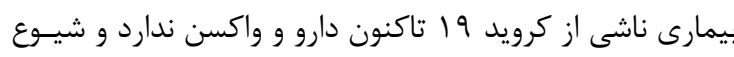

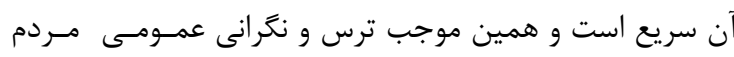

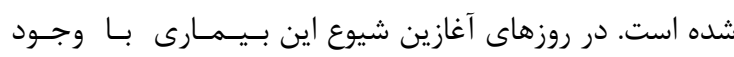

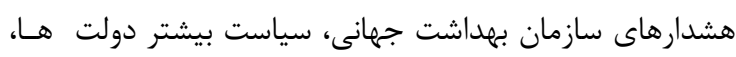

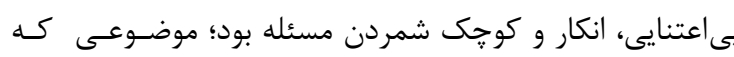

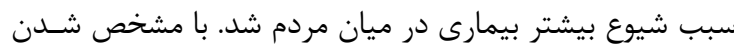

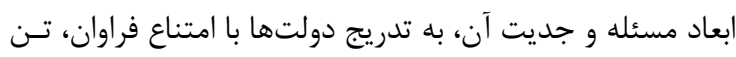

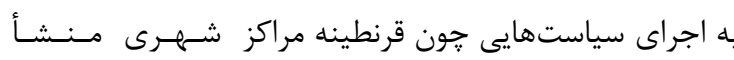

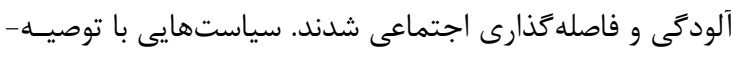
هايى جون "در خانه ماندن به صورت داوطلبانه و اعمال قوانيـن

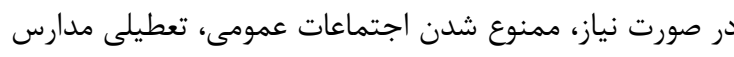

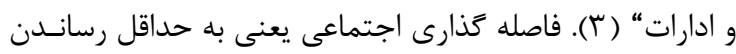

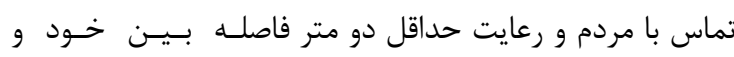

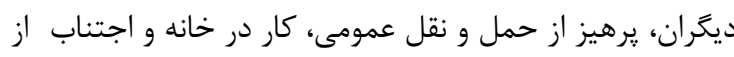

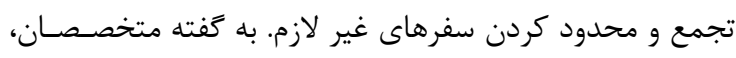

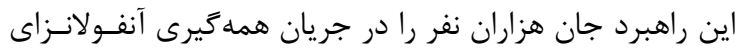

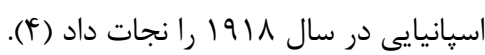

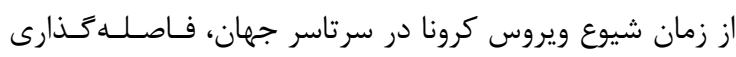

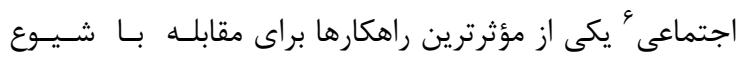

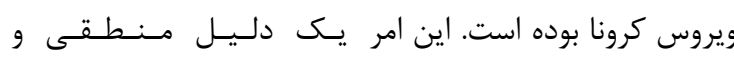

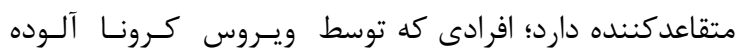

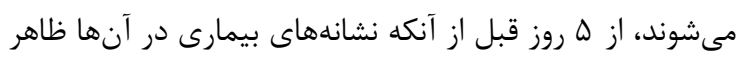

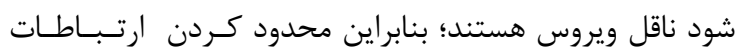

1- Covide -19 disease

2- SARS-CoV

3- Mers

5- Wuhan

6- Epidemic 


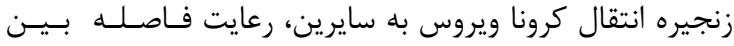

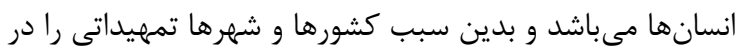
راستاى فاصله گذارى بين شهروندان خود، اتخاذ نمودهاند. كشور

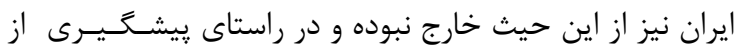

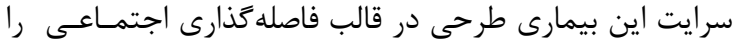

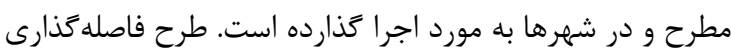

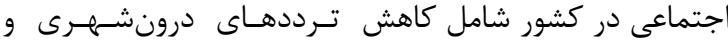

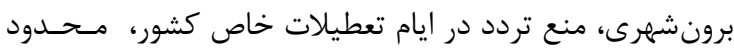

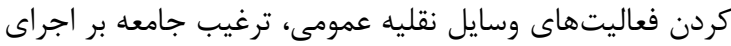

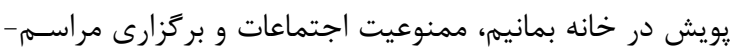

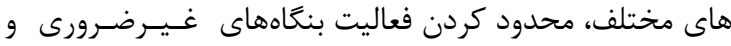

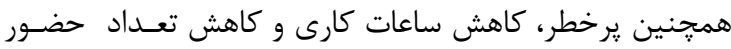

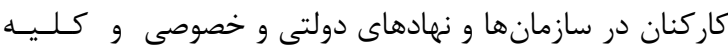

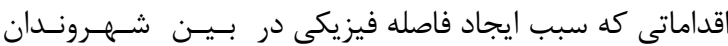

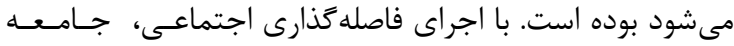

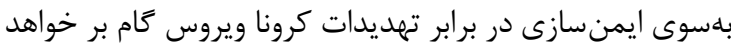

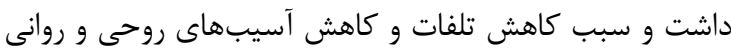

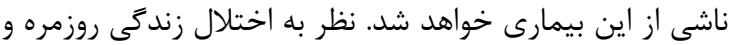

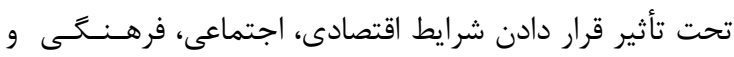

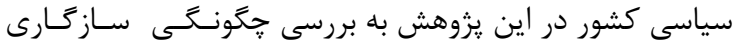

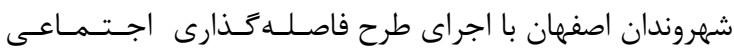

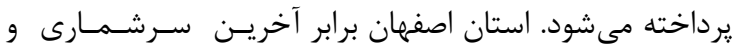

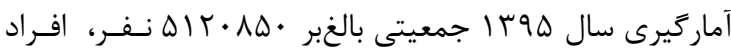
بومى و غيربومى استان اصفهان را در خود جاىداده است و تنوع

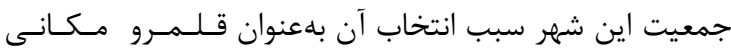

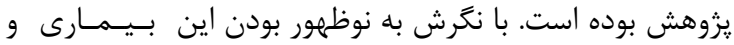

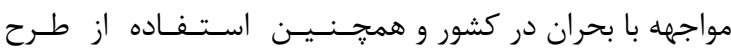
فاصله كذارى اجتماعى با وسعت زياد در كشور براى اولين بـار، نوآورى يزوهش را سبب شده است و به علت انجام تحقـيـقــات

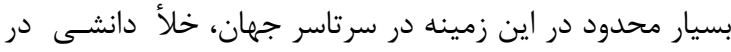

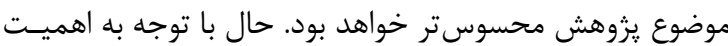

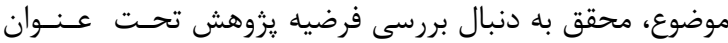

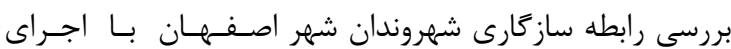

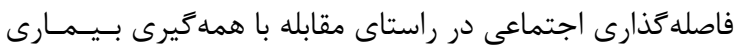

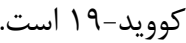

\section{روشكار}

يزوهش حاضر با رويكرد تحقيق كمى و استراترى توصيـفى و و

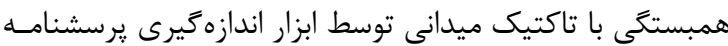

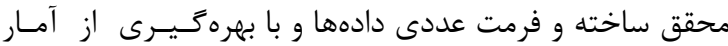

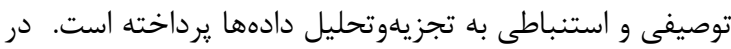
يروهش حاضر يرسشنامه محققساخته تدوين گرديده اسـت و و
موقع ملاقات اماكن عمومى بايد اجرا شود (V).

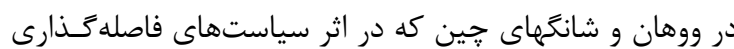

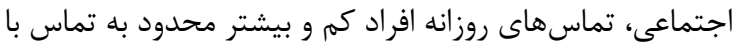

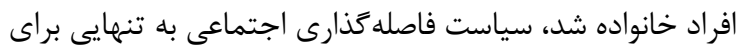
كنترل كوويد-19 در اين دو شهـر كـافى بـوده اسـت (^).

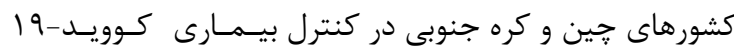

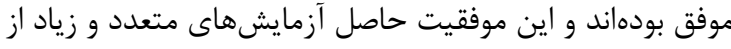

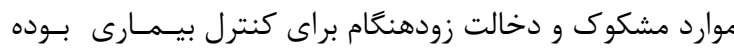

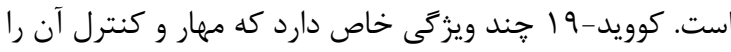
دشوار كرده است: شواهدى وجود دارد كه درحالى كه هنوز علائم

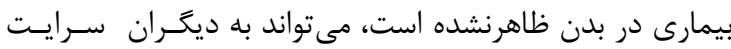

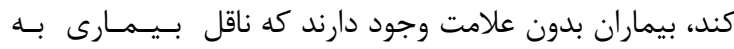

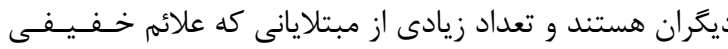

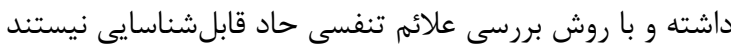
وجود دارند كه در جامعه حضورداشته و ريسك انتقال بيمارى را راسئ

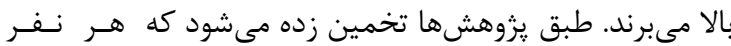

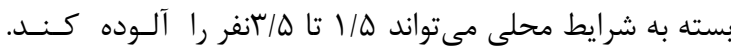

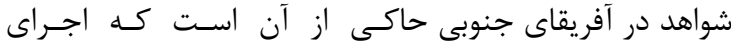

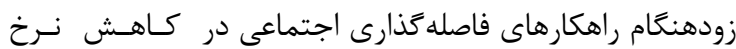
انتشار اييدمى كوويد-9 الدر اين كشور تأثير بسيار زيادى داشته داصده

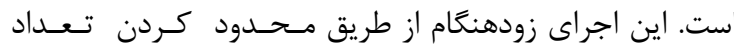

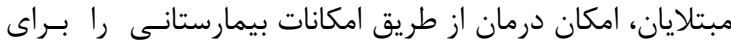

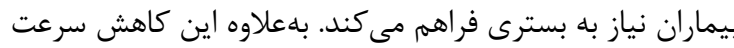

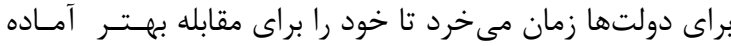

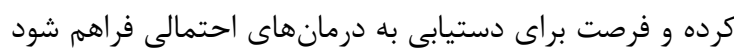

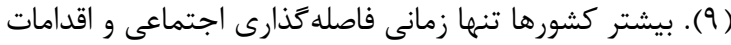

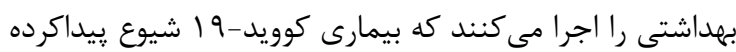

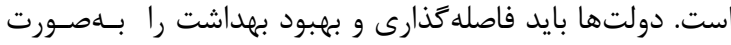

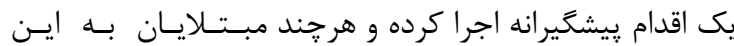
بيمارى در كشورشان كم باشد، به اجراى اين سياستها اقـدام

كنند (•) بل (1).

در اواخر سال 19 با كشور با بحران بيمارى واگيردار كوويد-19

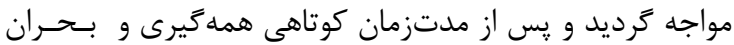

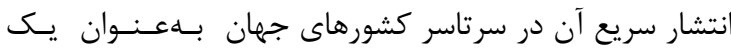

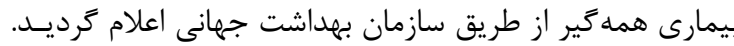

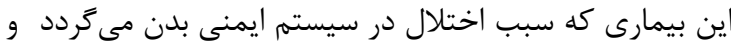

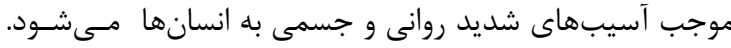

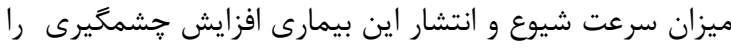

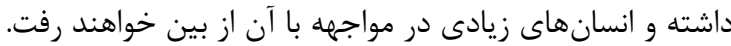

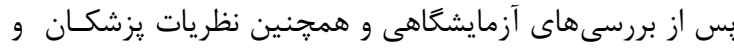

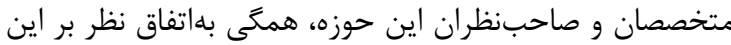

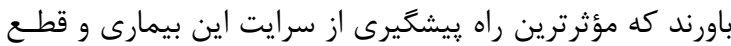


و رابطه بين متغير اصلى يزوهش و متغيرهاى جمعيت شناختى

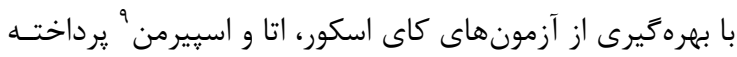

\section{يافته ها}

تركيب وضعيت تأهل اعضاى نمونه برابر فراوانى مشاهــدهــــه، r

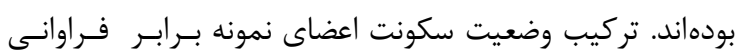
مشاهدهده، وه درصد ياسخدهند

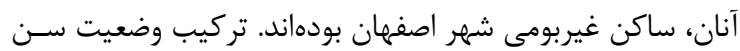

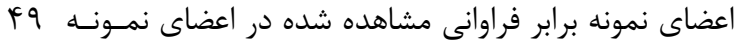
درصد ياسخدهند

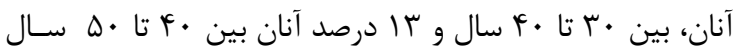

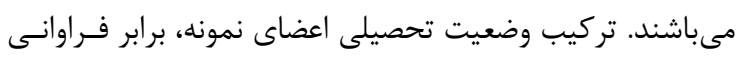

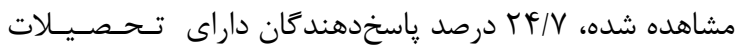

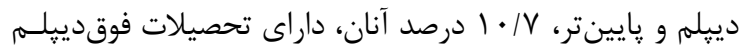

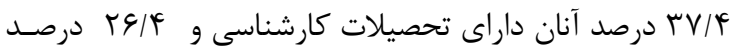

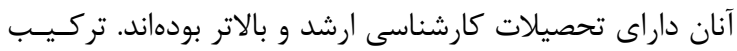

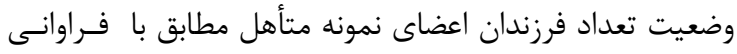

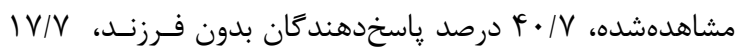

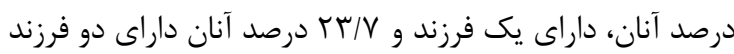
و و/V درصد آنان داراى سه فرزند بودهاند.
روايى آن توسط كارشناسان و تعدادى از اساتيد دانشعاه مــورد

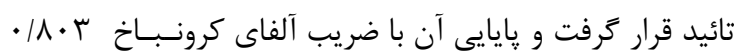

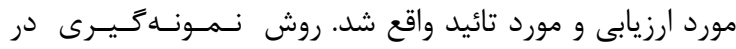

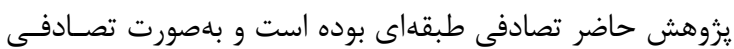

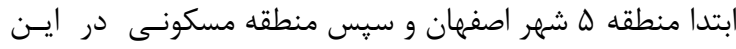

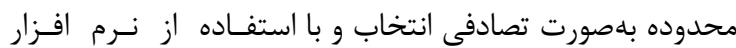

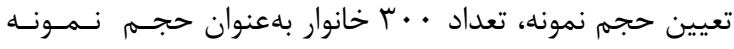

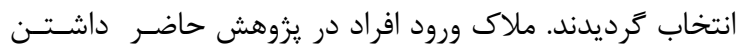

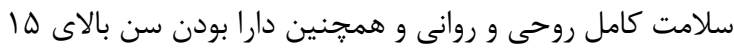

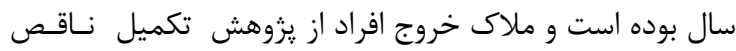

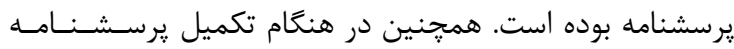

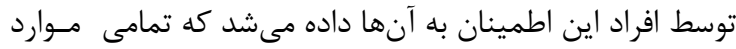

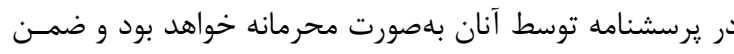
اينكه هويت افراد به دليل عدم خواستن نام و نام خانوادگى و ويا

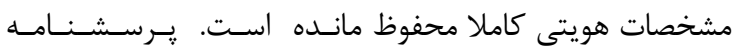

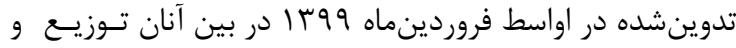

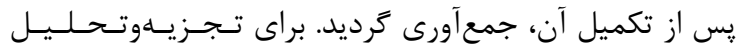

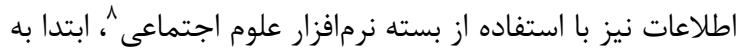

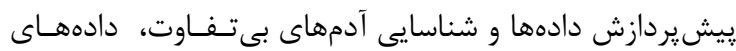

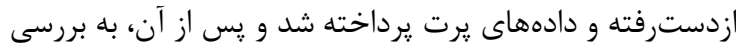

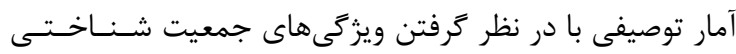

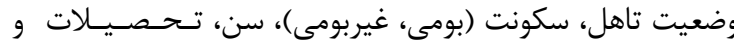

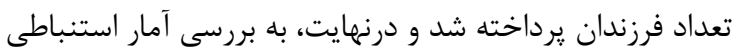

\begin{tabular}{|c|c|c|c|c|c|c|}
\hline جولخى & كشيدَّى & كمينه & بيشينه & انحراف معيار & ميانگين & متغير فاصله گذارى \\
\hline - & $\cdot 199$ & 1 & $\Delta$ & $1 / \mu k$ & r/ & اجتماعى \\
\hline
\end{tabular}

\section{جدول ا.آمار توصيفى شاخصهاى اندازهَيرى كننده متغيرها}

اجتماعى شهروندان شهر اصفهان مىباشد. ازآنجاكه مقدار

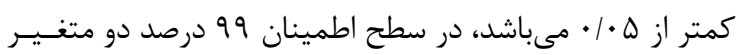

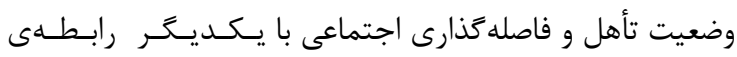
معنادارى دارند و شدت رابطه بسيار ضعيف مى باشد و فرضئه

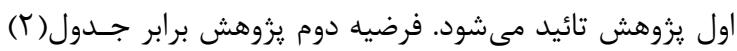

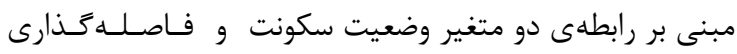
اجتماعى شهروندان شهر اصفهان مىباشد. ازآنجاكه مقدار

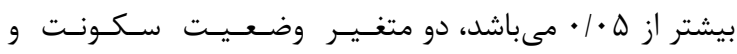

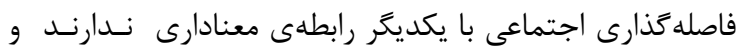
فرضيهى دوم يزوهش رد مىشود.
با توجه به اينكه شاخصهاى اندازهيرى كننده متغـيـر ماراى

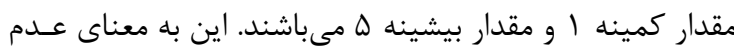

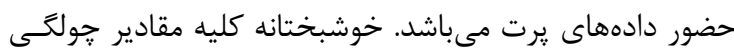

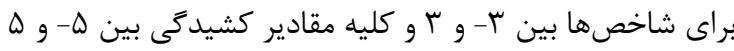

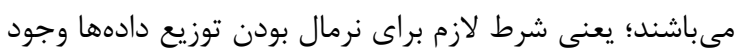

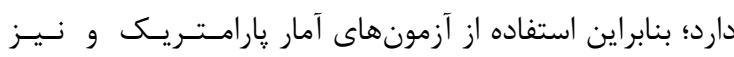

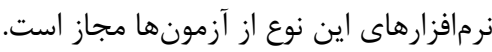

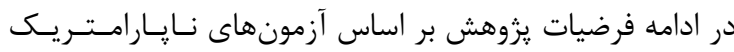

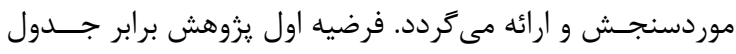

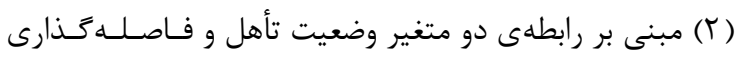

\begin{tabular}{|c|c|c|c|c|c|}
\hline نتيجه فرضيه & شدت رابطه & خطاى محاسبهشده & اتا & كاى اسكور & فرضيات \\
\hline تائيد فرضيه & بسيار ضعيف & $\cdot 1 \cdot \cdots$ & .1 .99 & FF/VF & فرضيه اول \\
\hline رد فرضيه & عدم رابطه & $\cdot 1 \cdot \mathrm{VV}$ & $\cdot|\cdot| q \mid$ & 19/DTV & فرضيه دوم \\
\hline
\end{tabular}


|زآنجاكه مقدار SIG بيشتر از ه • • • مىباشد، دو متغير وضعيت

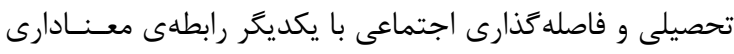

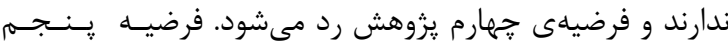

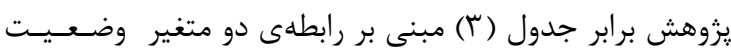
تحصيلى پاسخدهند

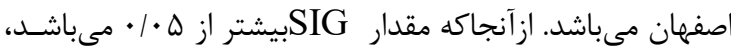

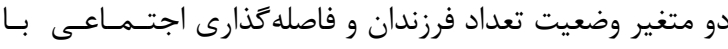

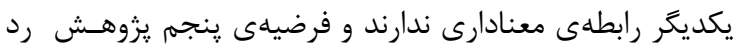

فرضيه سوم يزوهش برابر جدول (r) مبنى بر رابطهى دو متغير وضعيت سنى ياسخدهند كان و فاصله كذارى اجتماعى شهروندان

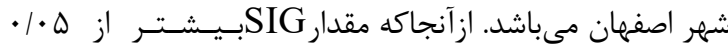

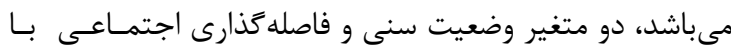

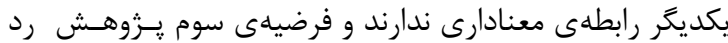

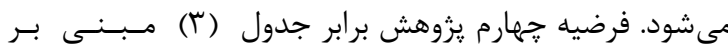

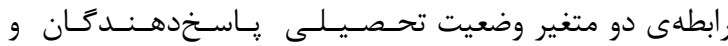

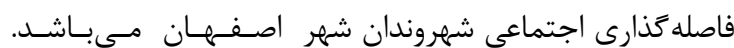

مىشود.

\begin{tabular}{|c|c|c|c|c|}
\hline نتيجه فرضيه & شدت و جهت رابطه & خطاى محاسبهشده & اسيّيرمن & فرضيات \\
\hline رد فرضيه & عدم رابطه & $\cdot / \uparrow \wedge \Delta$ & $\cdot / \cdot r$. & فرضيه سوم \\
\hline رد فرضيه & عدم رابطه & $\cdot /$ FV &.$/ \cdot$ et & فرضيه جهارم \\
\hline رد فرضيه & عدم رابطه & $\cdot / r 91$ & $-\cdot / \cdot \wedge 1$ & فرضيه ينجمم \\
\hline
\end{tabular}

\section{جدول ץ.آزمون فرضيههاى سوم، جهمارم و پنججم يزوهش}

كردن راهبردها سهلالوصولتر خواهد بود؛ كه اين امر مستـــزم ورود همهجانبه اقشار با سياست كذارى صحيح و نقشه راه راه درست

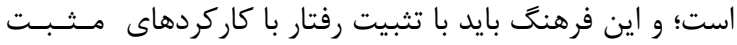
مسئوليت يذير كردن اجتماع در جامعه نهادينه كردد. ايجاد رفتار

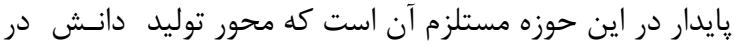

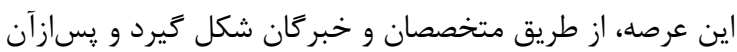

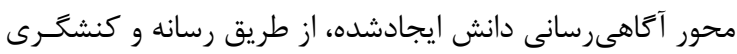

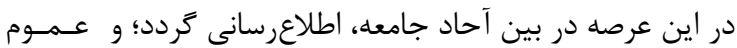

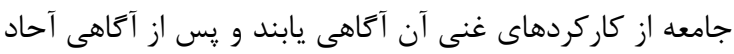

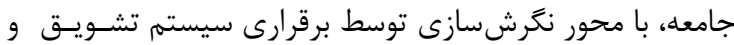

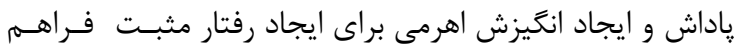

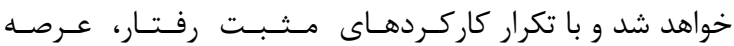
مسئوليت يذيرى اجتماعى بلهورت تدريجى به نخرش درونى در

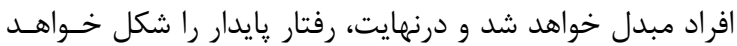

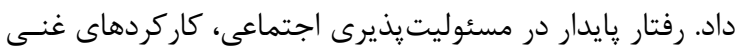

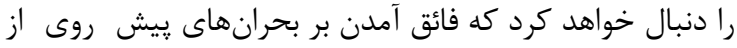

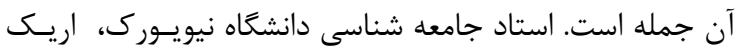

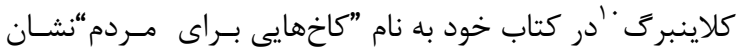

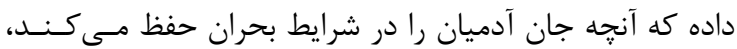

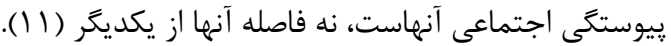

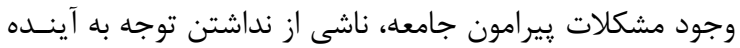

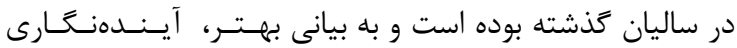

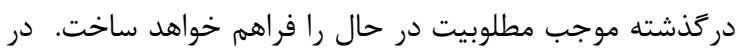

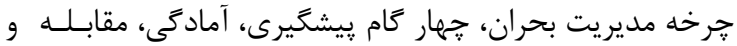

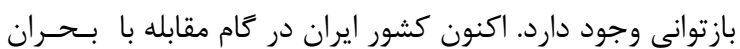

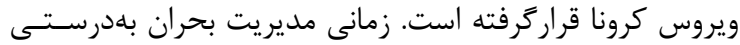

10- Klinenberg
بحث و نتيجه كيرى

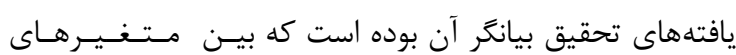

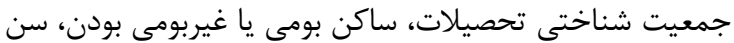

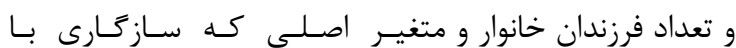
فاصله حذارى اجتماعى بوده است؛ رابطه معنادارى ايجاد نكرديده

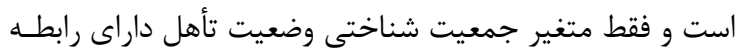

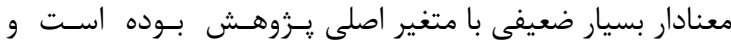

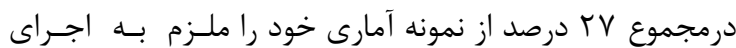
يو يش در خانه بمانيم و رعايت فاصله كذارى اجتماعى دانستهاند.

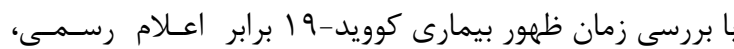

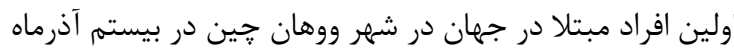

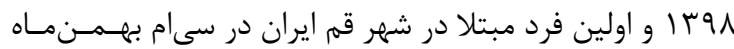

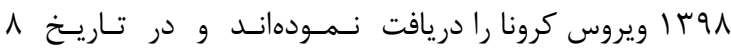

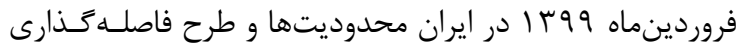

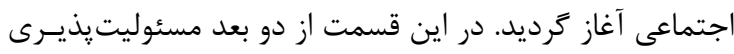

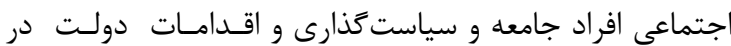

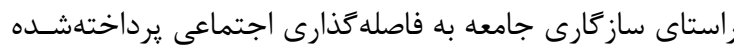

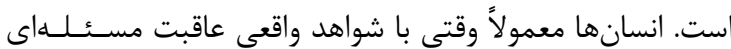

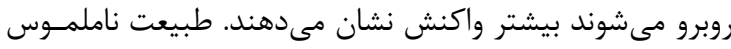

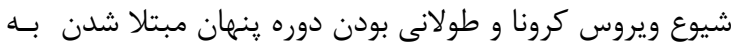

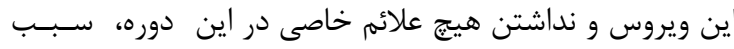
ديرتر به فكر افتادن افراد در قرنطينه كردن خود در خانه استـ؛

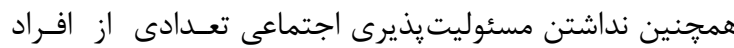

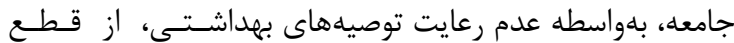

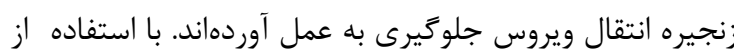

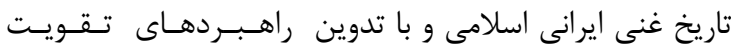

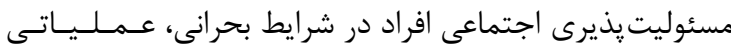


برخى از محدوديتها، هشدارها و تلاش دولت به علت فــاهـم

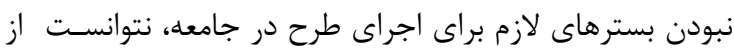

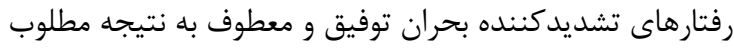

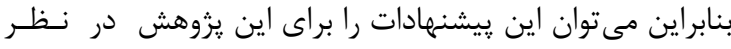

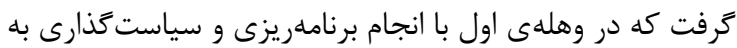
سمت ايجاد رفتار يايدار در راستاى مسئوليتيذيرى اجتماعى و و

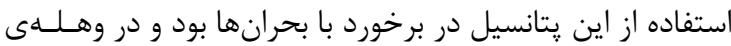

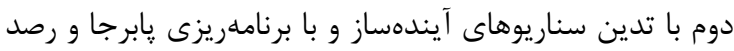
كردن شاخصهاى موثر بر مديريت بحران، كشور با اطمـيــــان

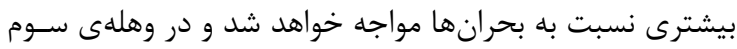

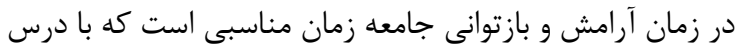

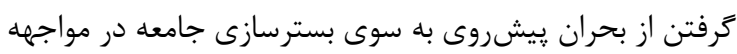
با : جنين بحران هايى اقدام شود.

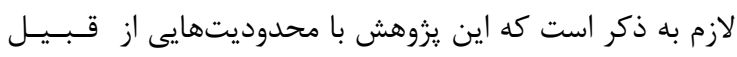

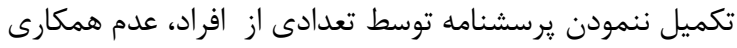

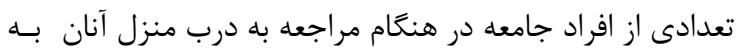
علت شيوع ويروس كرونا و ترس از ابتلا همراه بوده است.

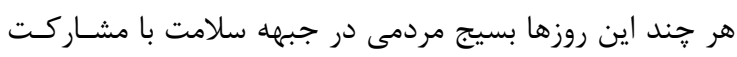

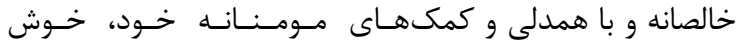

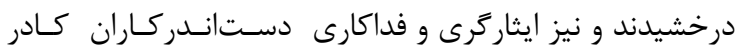

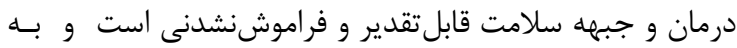

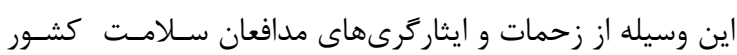
تشكر و قدردانى مى

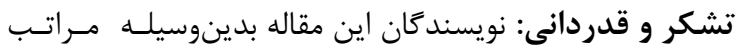

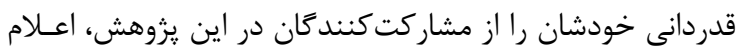

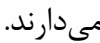

انجام شده است كه جرخه باصصورت كامل به مرحله اجرا كذارده

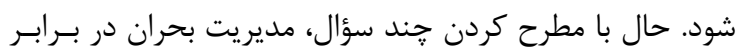

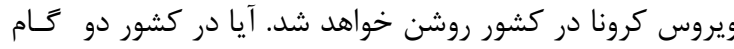

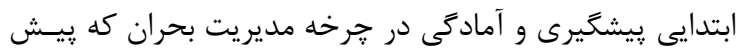

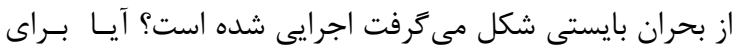

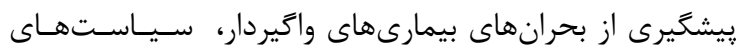

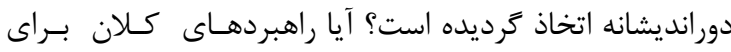

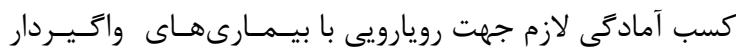

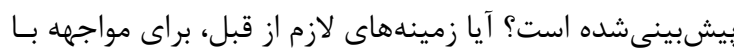

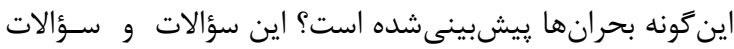

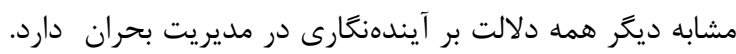

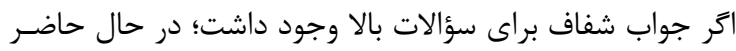

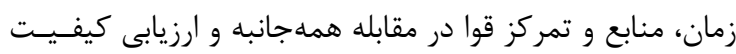

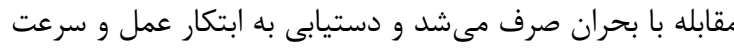

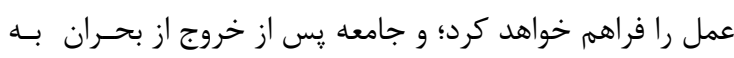

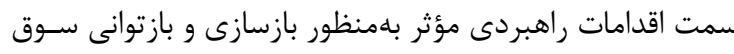

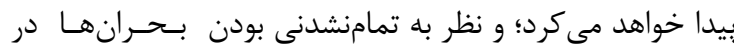

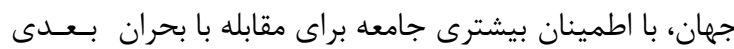

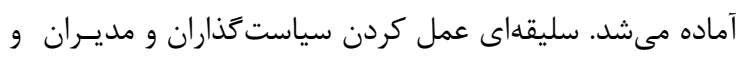

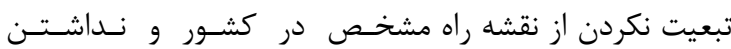

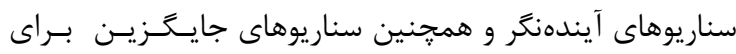

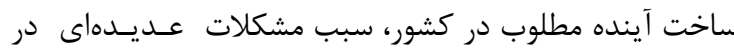

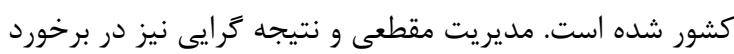

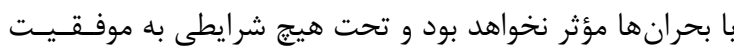

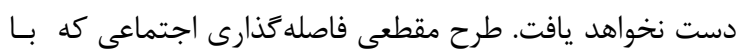

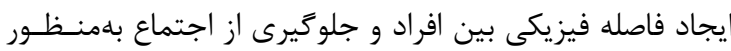

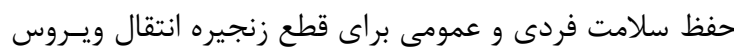

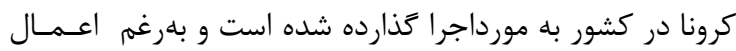




\section{References:}

1-Perlman S. Another decade, another coronavirus. The new england journal of medicine, 2020; 760-762.

2-Anderson RM, Heesterbeek H, Klinkenberg D, Hollingsworth TD. How will country-based mitigation measures influence the course of the COVID-19 epidemic?. The Lancet, 2020; 395 (10228): 931-934.

3-Barry J M. The Great Influenza: The Story of the Deadliest Pandemic in History. Penguin Books, 2005; pp 546.

4-Li Q, Guan X, Wu P, Wang X, Zhou L, Tong Y, Ren R, Leung KS, Lau EH, Wong JY, Xing $X$. Early transmission dynamics in Wuhan, China, of novel coronavirus-infected pneumonia. New England Journal of Medicine, 2020; 1 -9 .

5-Long NJ. From social distancing to social containment: reimagining sociality for the coronavirus pandemic. Medicine Anthropology Theory, 2020; 1-9.

6-Lewnard JA, Lo NC. Scientific and ethical basis for social-distancing interventions against COVID-19. The Lancet. Infectious diseases. 2020; (6):631-633
7-Wang C, Horby PW, Hayden FG, Gao GF. A novel coronavirus outbreak of global health concern. The Lancet. 2020; 395(10223):470473.

8-Zhang J, Litvinova M, Liang Y, Wang Y, Wang W, Zhao S, Wu Q, Merler S, Viboud C, Vespignani A, Ajelli M. Age profile of susceptibility, mixing, and social distancing shape the dynamics of the novel coronavirus disease 2019 outbreak in China. medRxiv, 2020; 1-31. 9-Preiser W, Van Zyl G, Dramowski A. COVID-19: Getting ahead of the epidemic curve by early implementation of social distancing. South African Medical Journal, 2020; 110(4): 258.

10-Dalton CB, Corbett SJ, Katelaris AL. Preemptive low cost social distancing and enhanced hygiene implemented before local COVID-19 transmission could decrease the number and severity of cases. The Medical Journal of Australia, 2020; 212(10): 1-10.

11-Klinenberg E. Palaces for the people: How social infrastructure can help fight inequality, polarization, and the decline of civic life. Broadway Books, 2018; 8. 